\title{
Cellular Senescence in Livers from Children with End Stage Liver Disease
}

\author{
Gabriela Gutierrez-Reyes ${ }^{19}$, Maria del Carmen Garcia de Leon ${ }^{19}$, Gustavo Varela-Fascinetto ${ }^{2}$, Pedro \\ Valencia', Ruy Pérez Tamayo', Claudia Gonzalez Rosado', Blanca Farfan Labonne', Norma Morales \\ Rochilin ${ }^{1}$, Rosalinda Martinez Garcia ${ }^{1}$, Jonathan Aguirre Valadez ${ }^{1}$, Gabriela Togno Latour ${ }^{1}$, Dana Lau \\ Corona ${ }^{1}$, Guillermo Robles Diaz ${ }^{1}$, Albert Zlotnik ${ }^{3}$, David Kershenobich ${ }^{1 *}$
}

1 Department of Experimental Medicine, School of Medicine, Universidad Nacional Autónoma de México (UNAM), Mexico City, Mexico, 2 Department of Surgery and Pathology, Hospital Infantil de México Federico Gomez, Mexico City, Mexico, 3 University of California Irvine, Irvine, California, United States of America

\begin{abstract}
Background: Senescent cells occur in adults with cirrhotic livers independent of the etiology. Aim: Investigate the presence rate of cellular senescence and expression of cell cycle check points in livers from children with end stage disease.

Methodology/Principal Findings: Livers of five children aged three years or less undergoing liver transplantation due to tyrosinemia $(n=1)$, biliary atresia $(n=2)$, or fulminant hepatitis $(n=2)$ were analyzed for senescence associated $\beta$ galactosidase (SA- $\beta$ gal) activity and p16INK4a, p21cip1 and p53. All livers displayed positive cellular staining for SA- $\beta$ gal in the canals of Hering and interlobular biliary ducts. In the presence of cirrhosis ( $3 / 5$ cases) SA- $\beta$ gal was found at the cholangioles and hepatocytes surrounding the regenerative nodules. Children with fulminant hepatic failure without cirrhosis had significant ductular transformation with intense SA- $\beta$ gal activity. No SA- $\beta$ gal activity was evident in the fibrous septa. Staining for $\mathrm{p} 53$ had a similar distribution to that observed for SA- $\beta$ gal. Staining for $\mathrm{p} 16^{\mathrm{INK} 4 \mathrm{a}}$ and $\mathrm{p} 21^{\mathrm{cip} 1}$ was positive in the explanted liver of the patient with tyrosinemia, in the hepatocytes, the canals of Hering, cholangioles and interlobular bile ducts. In the livers with fulminant hepatitis, p $21^{\text {cip } 1}$ staining occurred in the areas of ductular transformation and in the interlobular bile ducts.

Conclusions/Significance: Cellular senescence in livers of children with end stage disease is associated with damage rather than corresponding to an age dependent phenomenon. Further studies are needed to support the hypothesis that these senescence markers correlate with disease progression.
\end{abstract}

Citation: Gutierrez-Reyes G, Garcia de Leon MdC, Varela-Fascinetto G, Valencia P, Pérez Tamayo R, et al. (2010) Cellular Senescence in Livers from Children with End Stage Liver Disease. PLoS ONE 5(4): e10231. doi:10.1371/journal.pone.0010231

Editor: Mikhail V. Blagosklonny, Roswell Park Cancer Institute, United States of America

Received November 17, 2009; Accepted March 23, 2010; Published April 21, 2010

Copyright: (c) 2010 Gutierrez-Reyes et al. This is an open-access article distributed under the terms of the Creative Commons Attribution License, which permits unrestricted use, distribution, and reproduction in any medium, provided the original author and source are credited.

Funding: This study was supported by CONACYT-SALUD (Mexico), grant (2004-C01-175) and Universidad Nacional Autónoma de México (UNAM) grant (NEEGPSP SDI.PTID.05.6.) The funders had no role in study design, data collection and analysis, decision to publish, or preparation of the manuscript.

Competing Interests: The authors have declared that no competing interests exist.

*E-mail: kesdhipa@yahoo.com

9 These authors contributed equally to this work.

\section{Introduction}

In contrast to other types of cellular responses such as necrosis or apoptosis, the role of cellular senescence in the living organism is still not well understood. Senescence was originally described in human fibroblasts as a terminal non dividing stage reached after many cell divisions in cultures [1] Senescent cells remain alive, metabolically active and resistant to apoptotic death but are arrested in the Gl phase of the cell cycle, are resistant to growth factor stimulation and show common biochemical markers, such as expression of an SA- $\beta$ gal enzyme [2-3]. While senescence has been characterized primarily in cultured cells, there is also evidence that it occurs in vivo [4-6].

An increase in liver cells staining positive for SA- $\beta$ gal has been demonstrated in adults with cirrhotic livers independent of the etiology, including chronic viral hepatitis, autoimmune liver disease, primary biliary cirrhosis and chronic alcoholic liver disease; in these situations, chronic liver damage has been related to oxidative stress or telomere shortening, eventually culminating in replicative senescence [6-9]. Senescence has also been described to be associated to the progression of fibrosis in hepatitis $\mathrm{G}$ virus recurrence after liver transplantation, where a correlation has been observed between ischemic necrosis and replicative senescence on the revascularization biopsy, suggesting that livers containing senescent cells may be more sensitive to ischemia [10].

The genes associated with senescence have for the most part been tumor suppressor genes believed to be involved in the underlying mechanisms of replicative and stress-induced senescence [11-15]. p53 functions as a central integration point for various signaling pathways of senescence and inhibits cell division primarily through a p $21^{\mathrm{cip} 1}$ pathway [16-18]. The phosphorylated p53 upregulates transcription of the target gene p $21^{\text {cip } 1}$, which in turn activates $\mathrm{pRb}$ through inhibition of a cyclin-dependent kinase (Cdk) complex [19]. The activated pRb inhibits the transcription 
of E2F target genes, which are required for cell cycle progression. Another Cdk inhibitor, p16 ${ }^{\mathrm{INK} 4 \mathrm{a}}$, which also activates $\mathrm{pRb}$, accumulates in senescent cells and is considered essential in stressinduced senescence [13,14,20,21,22].

In this study, we report the presence of senescence biomarkers, including SA- $\beta$ gal activity and the expression of $\mathrm{p} 53, \mathrm{p} 21^{\mathrm{cip} 1}$, and $\mathrm{p} 16^{\mathrm{INK} 4 \mathrm{a}}$, in liver from children with end stage liver disease that required transplantation.

\section{Results}

\section{Analysis of the explanted livers}

The liver of the patient with cirrhosis secondary to tyrosinemia (case 1) exhibited, on cut sections, multiple nodules that varied in size from 0.2 to $2.0 \mathrm{~cm}$. The hepatocytes differed in size and shape, their cytoplasm contained lipid droplets, granular material and numerous mitochondria. Some had a dysplastic appearance with atypical nuclei. Fibrous septa of variable size were present; these hepatocytes had a variable immunohistochemical expression of nuclear proliferation factors and fetoproteins (data not shown). The dysplastic hepatocytes were not present in the initial diagnostic biopsy performed two years ago.

In the patients with extrahepatic biliary atresia (cases 2, 3) histology revealed the presence of micronodular cirrhosis. Active fibro-inflammatory septa with cholangiolar proliferation, mild lymphocytic infiltrate and cholestasis were found in case 2, while fibrous septa without bile ducts were observed in case 3 . When compared with the initial diagnostic biopsies, the explanted livers of the two patients showed that fibrosis had progressed and both had the typical changes of biliary cirrhosis.

In the children with fulminant hepatic failure (cases 4, 5) the liver had severe gross deformation, large areas of necrosis that were intermingled with nodules of residual hepatic parenchyma; huge necrotic zones were observed exhibiting a dense inflammatory infiltrate composed mainly of mononuclear cells. Immunohistochemical studies revealed, in case 4, a predominant B cell response with equal number of Kappa and Lambda cells, while in case 5 the cellular infiltrate was predominantly composed of $\mathrm{T}$ lymphocytes (CD3, CD45RO; data not shown).

Both livers exhibited significant ductular transformation.

\section{SA- $\beta$ gal activity}

$S A-\beta$ gal activity was detected in all five explanted livers. Its amount and distribution were heterogeneous. In all cases, staining was present in the canals of Hering and interlobular biliary ducts (TABLE 1). In the children with liver cirrhosis additional staining occurred in the cholangioles, and hepatocytes surrounding the regenerative nodules (Fig. 1A-B). In the livers of children with fulminant hepatic failure, intense staining was observed in the areas of ductal transformation (Fig. 1C). No SA- $\beta$ gal activity was evident in the fibrous septa. In the livers of the five normal donors (with normal histology) SA- $\beta$ gal activity was not detected.

\section{p53}

p53 staining had a similar distribution to that observed for SABgal activity, but was less common among the structures (TABLE 2). In the cirrhotic livers (Fig. 1D and F) p53 staining was found in the canals of Hering, interlobular bile ducts and the hepatocytes in the regenerative nodules. In the patients with fulminant hepatitis p53 was also found in the ductular transformation areas (Fig. 1E).

\section{p16 ${ }^{\text {INK4a }}$ and $\mathrm{p} 21^{\text {cip } 1}$}

Staining for $\mathrm{p} 16^{\mathrm{INK} 4 \mathrm{a}}$ and $\mathrm{p} 21^{\mathrm{cip} 1}$ was positive in the explanted liver of the patient with tyrosinemia in the hepatocytes, the canals of Hering, cholangioles and interlobular bile ducts (Fig. $1 \mathrm{G}-\mathrm{H}$ ) In the livers with fulminant hepatitis, p2 $1^{\text {cip } 1}$ staining occurred in the areas of ductal transformation and in the interlobular bile ducts (Fig. 1I; TABLE 2).

\section{Discussion}

Cellular senescence is usually considered an attribute of aging. Its presence in livers of young children with end stage hepatic disease, characterized by SA- $\beta$ gal activity accompanied by changes in the classical senescence pathway encompassing activation of $\mathrm{p} 53, \mathrm{p} 21^{\mathrm{cip} 1}$ and $\mathrm{p} 16^{\mathrm{INK} 4 \mathrm{a}}$, as found in the present study, support the concept that the loss of replicative capacity of the hepatocytes is related to liver damage.

Senescence markers were found for the most part in the Hering canals and the interlobular biliary ductules independent of the etiology of the underlying disease. All five children had an increased number of senescent cells accompanied with the expression of p53, reinforcing the concept of p53 as the major initiator of the senescence and a key regulator of DNA damage responses.

In the three cases with liver cirrhosis, the senescent hepatocytes were found predominantly around the regenerative nodules or inside of them (in lesser proportion) and absent in the fibrous septa. This distribution is similar to patterns previously described in adults [6]. In the two children with fulminant hepatic failure, senescent cells were displayed mainly at the site of the ductular

Table 1. SA- $\beta$ gal expression in the liver of children with end stage hepatic disease (\%).

\begin{tabular}{|c|c|c|c|c|c|c|}
\hline \multirow[t]{2}{*}{ Patient } & \multicolumn{2}{|c|}{ Nodule Hepatocytes } & \multirow[t]{2}{*}{$\begin{array}{l}\text { Canals of } \\
\text { Hering }\end{array}$} & \multirow[t]{2}{*}{$\begin{array}{l}\text { Ductular } \\
\text { Transformation }\end{array}$} & \multirow[t]{2}{*}{$\begin{array}{l}\text { Interlobular } \\
\text { bile ducts }\end{array}$} & \multirow[t]{2}{*}{ Cholangioles } \\
\hline & Central & Periphery & & & & \\
\hline 1 & 5 & 10 & 100 & NO & 100 & 100 \\
\hline 2 & 30 & 50 & 60 & NO & 100 & 60 \\
\hline 3 & Neg & 20 & 10 & NO & NO & 10 \\
\hline 4 & Col & Col & 100 & 90 & 100 & neg \\
\hline 5 & neg & neg & 100 & 50 & 100 & NO \\
\hline
\end{tabular}



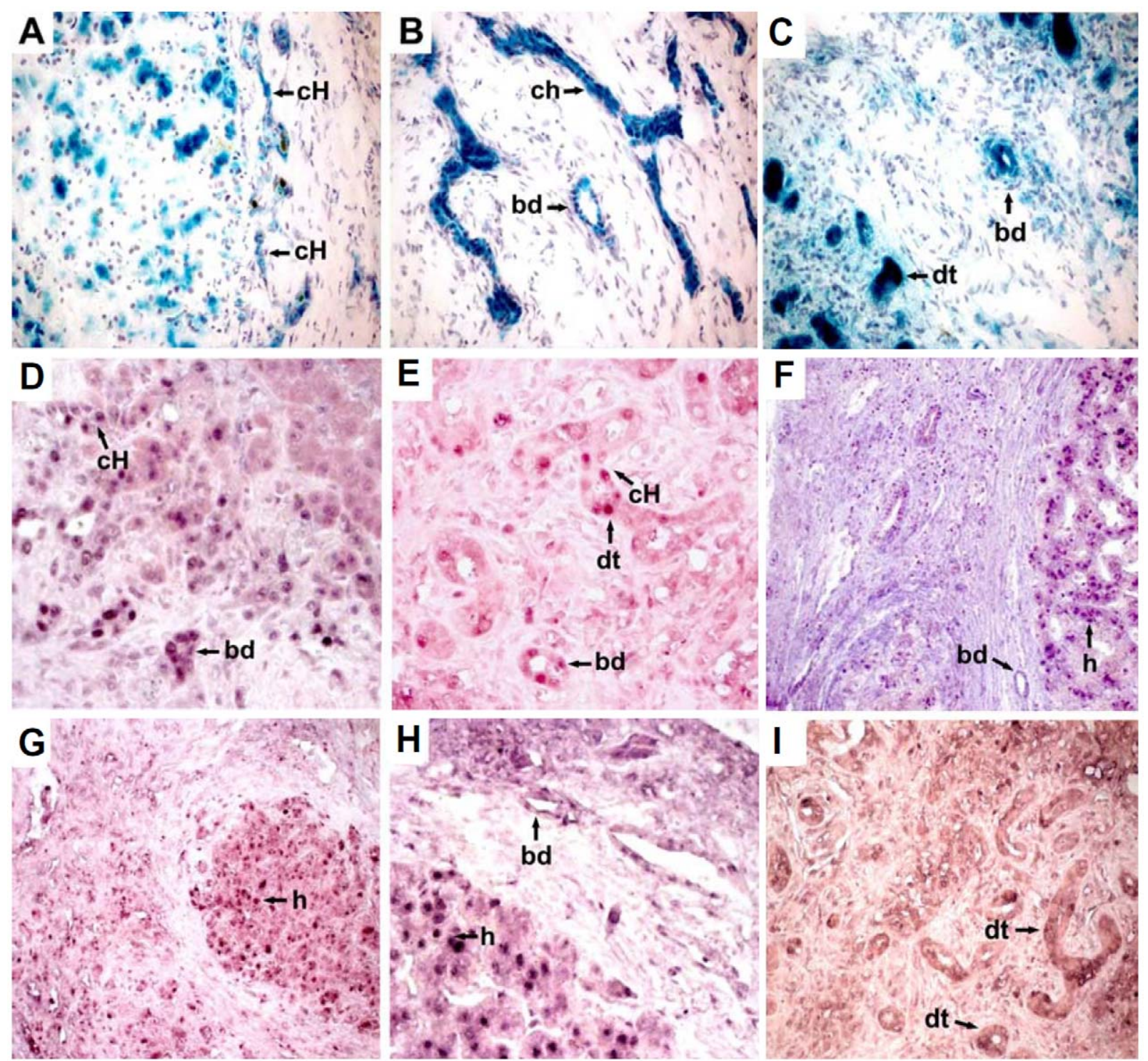

Figure 1. Representative images of senescence associated marker ( $\beta$-galactosidase) and cell cycle markers (p16 ${ }^{\text {INK4a }}$, p21 ${ }^{\text {cip } 1}$ and p53). SA- $\beta$ gal expression (turquoise blue) in fresh liver sections of the recipients with end stage liver disease. (A-B) Intense SA- $\beta$ gal in canals of

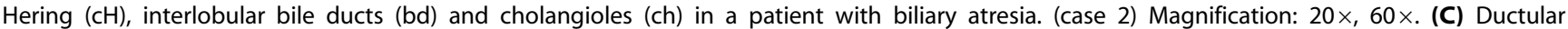
transformation of hepatocytes (dt) exhibiting SA- $\beta$ gal in a patient with fulminant hepatic failure (case 4). Magnification: $40 \times$. (D-I) Nuclear staining in formalin fixed paraffin embedded livers with end stage liver disease. (D) p53 canals of Hering (cH) and interlobular bile ducts (bd) in a patient with biliary atresia (case 3). (E) Canals of Hering (cH), interlobular bile ducts (bd) and hepatocyte ductular transformation (dt) in a patient with acute liver failure (case 4). (F) Hepatocytes in the regenerative nodules (h) and in the bile duct in the fibrotic bands (bd) in a patient with tyrosinemia (case 1), Magnification: $40 \times$. (G) p16 $16^{\text {NKKa }}$ staining in the hepatocytes (h) inside a regenerative nodule (case 1). Magnification: $20 \times$, (H) p2 cip1, staining in bile duct (bd) in the fibrotic bands and in the hepatocytes (h) inside a regenerative nodule (case 1). Magnification: $40 \times$. (I) p2 ${ }^{\text {cip } 1}$ staining in the nuclei of cells that aggregate to form ductular transformation structures (dt) (case 4). Magnification $40 \times$.

doi:10.1371/journal.pone.0010231.g001

transformation of the hepatocytes plate. It is now accepted that the atypical ductular reaction observed in livers with sub-massive hepatitis represents the proliferation of hepatic progenitor cells, similar to rat oval cells and are able to differentiate towards the biliary and the hepatocytic lineage [23-24]. Whether the ductular reaction observed in this study in the two children with fulminant hepatic failure represents an activated stem cell response or biliary metaplasia of cholestatic injured hepatocytes is not clear. When we used an antibody directed to CK7 (as a marker of biliary epithelium), approximately $60 \%$ of the staining was present in the tubular structures and all the staining was found in cells located in the canals of Hering (data not shown). The latter represent the anatomic and physiologic link between the intralobular canalicular system and the terminal branches of the biliary tree, suggesting that hepatocytes could have differentiated into biliary cells that aggregate to form the ductular structures [25] Transplantation of rat hepatocytes into a syngeneic rat spleen results in the appearance of CK 7 positive biliary cells that form ductules [26]. p21 is recognized as a valuable check point for evaluating proliferative activity/proliferation arrest of hepatocytes. In the case of fulminant hepatitis were more than $50 \%$ of hepatocytes where lost, p21 was found to be expressed in the ductular area 
Table 2. Expression of senescence markers in the liver of children with end stage hepatic disease (\%).

\begin{tabular}{|c|c|c|c|c|c|c|c|c|c|c|c|c|c|c|c|c|c|c|}
\hline \multirow[t]{3}{*}{ Patient } & \multicolumn{6}{|c|}{ Nodule Hepatocytes } & \multicolumn{3}{|c|}{$\begin{array}{l}\text { Canals } \\
\text { of Hering }\end{array}$} & \multicolumn{3}{|c|}{$\begin{array}{l}\text { Ductular } \\
\text { Transformation }\end{array}$} & \multicolumn{3}{|c|}{$\begin{array}{l}\text { Interlobular } \\
\text { bile ducts }\end{array}$} & \multicolumn{3}{|c|}{ Cholangioles } \\
\hline & \multicolumn{3}{|c|}{ Central } & \multicolumn{3}{|c|}{ Periphery } & \multirow[b]{2}{*}{ p16 } & \multirow[b]{2}{*}{ p21 } & \multirow[b]{2}{*}{ p53 } & \multirow[b]{2}{*}{ p16 } & \multirow[b]{2}{*}{ p21 } & \multirow[b]{2}{*}{ p53 } & \multirow[b]{2}{*}{ p16 } & \multirow[b]{2}{*}{ p21 } & \multirow[b]{2}{*}{ p53 } & \multirow[b]{2}{*}{ p16 } & \multirow[b]{2}{*}{ p21 } & \multirow[b]{2}{*}{ p53 } \\
\hline & p16 & p21 & p53 & p16 & p21 & p53 & & & & & & & & & & & & \\
\hline 1 & 85 & 80 & 75 & 85 & 80 & 75 & 100 & 100 & 70 & NO & NO & NO & 35 & 100 & 15 & 100 & 100 & Neg \\
\hline 2 & neg & neg & neg & neg & neg & 10 & neg & neg & 30 & NO & NO & NO & neg & neg & 30 & neg & neg & 50 \\
\hline 3 & neg & neg & 20 & neg & neg & 50 & neg & neg & 60 & NO & NO & NO & neg & neg & 30 & neg & NO & 30 \\
\hline 4 & Col & Col & Col & Col & Col & Col & 100 & neg & 30 & 30 & 50 & 80 & 30 & 20 & 30 & neg & neg & 50 \\
\hline 5 & Col & Col & Col & Col & $\mathrm{Col}$ & Col & neg & neg & $>10$ & 50 & neg & 80 & 100 & 20 & 30 & NO & NO & NO \\
\hline
\end{tabular}

where regeneration and hepatic progenitor cells probably fail in time to activate indicating disease severity. On the other hand the upregulated expression of p21 in the hepatocytes located in the regenerative nodules and its periphary in the case of tyrosinemia suggest the inhibition of cell proliferation and advance necrosis.

Overall, our findings point towards the equilibrium in the control of self-renewal and multilineage differentiation capacities of regenerative cells. For once the decline in the regenerative capacity and changes in number of functional stem/progenitor cells which at the same time may increase the risk to develop associated diseases and on the other the accumulation of genetic alterations leading to changes in regulation of numerous tumor suppressor genes. These processes in term could become be more relevant if deregulated signals from an aged niche, so as those of a small admixture of non dividing senescent cells could contribute to their dysfunctions or loss, which could account for some of the observed differences in time (chronic vs acute) of the patients herein reported. In order to further support the hypothesis that these senescence markers correlate with disease progression, it will be necessary to design studies including disease and age matched controls and to explore in more detail the possible mechanisms involved.

\section{Methods}

\section{Patients}

The study includes 5 consecutive patients aged three years or less with end stage liver disease due to tyrosinemia $(n=1)$ biliary atresia $(n=2)$ fulminant hepatitis $(n=2)$ who underwent liver transplantation at Mexico City's Children's Hospital (Hospital Infantil de Mexico). Complete clinical charts and pre-transplant liver biopsies were available for each case. The patients with liver cirrhosis due to tyrosinemia and biliary atresia had evidence of liver disease from the early days after being born. The patients with acute liver failure, one corresponded to an autoimmune etiology of seven months of progression with 30 days of acute liver failure and the other had nine days of disease progression of unknown etiology. The two patients with biliary atresia and liver cirrhosis had portal hypertension and esophageal bleeding. The two patients with acute liver failure have severe encephalopathy. Three patients received a liver allograft from living relatives and two from deceased donors. The surgical procedure and sample collections were described in detail to the patients' parents and appropriate signed informed consent was obtained. The study was approved by the institutional review board of the Hospital Infantil de Mexico.

\section{Explanted liver analyses}

Sections from formalin fixed paraffin-embedded liver tissue were stained with haematoxylin and eosin, Masson's trichrome, PAS, PAS-diastase, modified orcein, reticulin Perl's iron, immunohistochemistry and special staining when necessary.

\section{SA- $\beta$ gal Activity}

Fresh tissue samples were used to detect activity of $\beta$ galactosidase at $\mathrm{pH}$ of 6.0 as marker of senescence. Surgical specimens were frozen immediately in OCT, cut into $5-\mu \mathrm{m}$ sections and fixed with glutaraldehyde at $0.2 \%$ for 10 minutes. After washing with lacZ at room temperature the specimens were stained for $14-18 \mathrm{hrs}$ at $37^{\circ} \mathrm{C}$ with fresh galactosidase staining solution. The solution contained $1 \mathrm{mg} / \mathrm{ml} \mathrm{5-bromo-4-}$ chloro-3-indolyl- $\beta$-D-galactoside (X-gal) (Sigma-Aldrich, St Louis, $M O, U S A)$. After staining, the specimens were washed twice with PBS. The specimens were counterstained with hematoxilin staining solution for one minute and washed twice in PBS. The cells with SA- $\beta$ gal activity showed a blue turquoise staining in the cytoplasm.

\section{Immunohistochemistry}

Deparaffinized tissue was microwave heated to retrieve antigen and reacted with full-length monoclonal antibodies to p53 (SigmaAldrich, St Louis, MO, USA) at a dilution of 1:50, p2 $1^{\text {cip1 }}$ at a dilution of 1:25 and p16 $6^{\mathrm{INK} 4 \mathrm{a}}$ at a dilution of 1:75, (Santa Cruz Biotechnology, Santa $\mathrm{Cruz}, \mathrm{CA}$ ) and incubated at $4^{\circ} \mathrm{C}$ overnight. A secondary antibody coupled with alkaline phosphatase was used to expose the reaction to the monoclonal antibodies; NBT/BCIP substrate was used as a chromogen. Carcinomatous colon tissue served as positive controls. Negative control slides were reacted with a non related antibody to Aspergillus niger (Dako Cytomation, Glostrup, Denmark) under similar conditions. Percentage of positive nuclear staining either weak or strong was noted. Quantification was performed by manual counting on 10 representative fields by two independent observers and photographed with a Nikon Microphot-FXA microscope. The mean of the scores counted by each of the observers was used as expression score.

An indirect immunohistochemical technique was utilized to stain for CK7 (Dako Cytomation, Glostrup, Denmark), employing a 
secondary antibody labeled with peroxidase and diaminobenzidine as a chromogen.

\section{Acknowledgments}

The authors thank Marco Gudiño for his help in histological imaging and Leticia Sanchez for her assistance.

\section{References}

1. Hayflick L, Moorhead PS (1961) The serial cultivation of human diploid cell strains. Exp Cell Res 25: 585-621.

2. Dimri GP, Lee X, Basile G, Acosta M, Scott G, et al. (1995) A biomarker that identifies senescent human cells in culture and in aging skin in vivo. Proc Natl Acad Sci USA 92: 9363-9367.

3. Maier A, Westendorp R, Van Heemst D (2007) Beta-galactosidase activity as a biomarker of replicative senescence during the course of human fibroblast cultures. Ann N Y Acad Sci 1100: 323-32.

4. Zhang $\mathrm{H}$ (2007) Molecular signaling and genetic pathways of senescence: Its role in tumorigenesis and aging. J Cell Physiol 210: 567-574.

5. Campisi J (2000) Cancer, aging and cellular senescence. In Vivo 14: 183-188.

6. Paradis V, Youssef N, Dargère D, Bâ N, Bonvoust F, et al. (2001) Replicative senescence in normal liver, chronic hepatitis $\mathrm{C}$ and hepatocellular carcinomas. Hum Pathol 32: 327-332.

7. Wiemann SU, Satyanarayana A, Tsahuridu M, Tillmann HL, Zender L, et al, (2002) Hepatocyte telomere shortening and senescence are general markers of human liver cirrhosis. FASEB J 16: 935-942.

8. Shawi M, Autexier C (2008) Telomerase,senescence and ageing. Mech Ageing Dev 129: 3-10.

9. Passos JF, Saretzki G, von Zglinicki T (2007) DNA damage in telomeres and mitochondria during cellular senescence: is there a connection? Nucleic Acids Res 35: 7505-7513.

10. Trak-Smayra V, Contreras J, Dondero F, Durand F, Dubois S, et al. (2004) Role of replicative senescence in the progression of fibrosis in hepatitis $\mathrm{C}$ virus (HCV) recurrence after liver transplantation. Transplantation 77: 1755-1760.

11. Kiss A, Schnur J, Szabó Z, Nagy P (2001) Immunohistochemical analysis of atypical ductular reaction in the human liver, with special emphasis on the presence of growth factors and their receptors. Liver 21: 237-246.

12. Seki S, Kitada T, Sakaguchi H, Iwai S, Kawada N, et al. (2003) Expression of progenitor cell markers in livers with fulminant massive necrosis. Hepatol Res 25: 149-157.

13. Martien S, Abbadie C (2007) Acquisition of oxidative DNA damage during senescence: the first step toward carcinogenesis? Ann N Y Acad Sci 1119: 51-63.

14. Chen JH, Ozanne SE, Hales CN (2007) Methods of cellular senescence induction using oxidative stress. Methods Mol Biol 371: 179-189.

\section{Author Contributions}

Conceived and designed the experiments: GGR MdGGdL GRD AZ DK. Performed the experiments: MdCGdL GGR NMR RMG JAV GTL DLG. Analyzed the data: GGR MdCGdL GVF PV RPT DK. Contributed reagents/materials/analysis tools: GVF PV. Wrote the paper: GGR MdCGdL DK. Performed some of the experiments: BFL.

15. Courtois-Cox S, Jones SL, Cichowski K (2008) Many roads lead to oncogeneinduced senescence. Oncogene 27: 2801-2809.

16. Yang S, Koteish A, Lin H, Huang J, Roskams T, et al. (2004) Oval cells compensate for damage and replicative senescence of mature hepatocytes in mice with fatty liver disease. Hepatology 39: 403-411.

17. Obata M, Imamura E, Yoshida Y, Goto J, Kishibe K, et al. (2001) Resistance of primary cultured mouse hepatic tumor cells to cellular senescence despite expression of p16(Ink4a), p19 (Arf) , p53 and p21 $1^{\text {(Waf 1/Cip1) }}$. Mol Carcinog 32: $9-18$.

18. Chen J, Huang X, Halicka D, Brodsky S, Avram A, et al. (2006) Contribution of p16INK4a and p21CIP1 pathways to induction of premature senescence of human endothelial cells: permissive role of p53. Am J Physiol Heart Circ Physiol 290: H1575-H1586.

19. Kuhlmann WD, Peschke P (2006) Hepatic progenitor cells, stem cells and AFP expression in models of liver injury. Int J Exp Pathol 87: 343-359.

20. Watanabe H, Hata M, Terada N, Ueda H, Yamada N, et al. (2008) Transdifferentiation into biliary ductular cells of hepatocytes transplanted into the spleen. Pathology 40: 272-276.

21. Bringold F, Serrano M (2000) Tumor suppressors and oncogenes in cellular senescence. Exp Gerontol 35: 317-329.

22. Takahashi A, Ohtani N, Yamakoshi K, Iida S, Tahara H, et al. (2006) Mitogenic signaling and the $\mathrm{p} 16^{\mathrm{INK} 4 \mathrm{a}}-\mathrm{Rb}$ pathway cooperate to enforce irreversible cellular senescence. Nat Cell Biol 8: 1291-1297.

23. Kenyon J, Gerson SL (2007) The role of DNA damage repair in aging of adult stem cells. Nucleic Acids Res 35: 7557-7565.

24. Ju YJ, Lee KH, Park JE, Yi YS, Yun MY, et al. (2006) Decreased expression of DNA repair proteins $\mathrm{Ku} 70$ and Mrel1 is associated with aging and may contribute to the cellular senescence. Exp Mol Med 38: 686-693.

25. Prieur A, Peeper DS (2008) Cellular senescence in vivo: a barrier to tumorigenesis. Curr Opin Cell Biol 20: 150-155.

26. Zwerschke W, Mazurek S, Stöckl P, Hütter E, Eigenbrodt E, et al. (2003) Metabolic analysis of senescent human fibroblasts reveals a role for AMP in cellular senescence. Biochem J 376: 403-411. 